\title{
Respuestas antioxidantes en dos ecotipos de Colobanthus quitensis (Caryophyllaceae) expuestos a alta radiación UV-B y baja temperatura
}

\author{
Antioxidant responses in two Colobanthus quitensis (Caryophyllaceae) ecotypes exposed to \\ high UV-B radiation and low temperature
}

\section{ALEJANDRO A. NAVARRETE-GALLEGOS ${ }^{1,}{ }^{*}$, LEÓN A. BRAVO ${ }^{2}$, MARCO A. MOLINA-MONTENEGRO ${ }^{3}$ \& LUIS J. CORCUERA ${ }^{1}$}

\begin{abstract}
${ }^{1}$ Laboratorio de Fisiología Vegetal, Departamento de Botánica, Universidad de Concepción, Casilla 160-C, Concepción, Chile ${ }^{2}$ Laboratorio de Fisiología y Biología Molecular Vegetal, Facultad de Ciencias Agropecuarias y Forestales, Universidad de La Frontera, Casilla 54 D, Temuco, Chile

${ }^{3}$ Centro de Estudios Avanzados en Zonas Áridas (CEAZA), Facultad de Ciencias del Mar, Universidad Católica del Norte, Coquimbo, Chile

*Autor correspondiente: anavarre@udec.cl
\end{abstract}

\begin{abstract}
RESUMEN
Colobanthus quitensis (Kunth) Bartl. (Caryophyllaceae) está distribuida desde México hasta la Antártida Marítima formando poblaciones adaptadas a distintas condiciones microambientales a lo largo de su distribución. La Antártica Marítima se caracteriza por una estación de crecimiento más fría y breve, con crecientes niveles de radiación UV-B. Los Andes de Chile Central, en cambio, tienen oscilaciones térmicas más amplias y una elevada tasa de radiación UV-B. El objetivo de este estudio es conocer las estrategias y mecanismos antioxidantes adoptadas por los ecotipos Antártico y Andino para tolerar los efectos dañinos de la radiación UV-B y el frío bajo condiciones controladas de laboratorio. Postulamos que los individuos de $C$. quitensis provenientes de la cordillera de Los Andes de Chile Central, donde los niveles de radiación UV-B son mayores que en la Antártica, tendrían un conjunto de mecanismos antioxidantes más eficaces para contrarrestar los efectos del UV-B y sufrirían menos daño que el ecotipo Antártico. Plantas cultivadas en laboratorio del ecotipo Antártico y Andino fueron sometidas a tres intensidades de radiación UV-B (70, 35 y $3 \mu \mathrm{W} \mathrm{cm}-2)$, a 4 y $15{ }^{\circ} \mathrm{C}$, respectivamente. En cada tratamiento se evaluaron las respuestas de la actividad antioxidante total (TAS), actividad de la enzima superóxido dismutasa (SOD) y características anatómicas foliares con un posible rol protector frente a UV-B. Finalmente, se evaluaron los efectos dañinos del UV-B, como son: acumulación de malonaldialdehido (MDA), eficiencia fotoquímica máxima del PSII y fotoinactivación. Ambos ecotipos mostraron reducción de área foliar y engrosamiento del parénquima. El ecotipo andino presentó mayores niveles de TAS con radiación UV-B media y alta. La actividad SOD máxima se midió en el ecotipo andino, encontrándose un aumento de hasta ocho veces el nivel basal a las cuatro horas de irradiación. El ecotipo antártico expuesto a UV-B y frío presentó un mayor daño a membranas (MDA), al igual que un mayor grado de fotoinactivación. Adicionalmente, se detectó la acumulación de una nueva isoforma $\mathrm{Cu}-\mathrm{Zn} / \mathrm{SOD}$, insensible a $\mathrm{H}_{2} \mathrm{O}_{2}$, en plantas tratadas con UV-B. En conclusión, el ecotipo andino presenta una respuesta antioxidante más efectiva contra el UV-B que el ecotipo antártico.
\end{abstract}

Palabras clave: Antártica, antioxidantes, daño oxidativo, UV-B.

\section{ABSTRACT}

Colobanthus quitensis (Kunth) Bartl. (Caryophyllaceae) is distributed from Mexico to the Maritime Antarctica forming colonies adapted to several micro environmental conditions along its distribution. The Maritime Antarctica is characterized by a colder and short season with increasing radiation levels of UV-B. On the other hand, The Andes range in Central Chile has ample thermal oscillations and a high UV-B radiation. The purpose of this study is to know the antioxidant strategies and mechanisms adopted by the C. quitensis Antarctic and Andean ecotypes to tolerate the damaging effects of the UV-B radiation and cold under controlled laboratory conditions. We postulate that individuals of $C$. quitensis from the Central Chilean Andes (Andean ecotype), where UV-B levels are higher than in the Antarctica, would have more effective antioxidant mechanisms than the Antarctic ecotype. Plants of the Antarctic and Andean ecotypes grown under laboratory were subjected to three intensities of UV-B radiation $(70,35$ y $3 \mu \mathrm{W} \mathrm{cm}-2), 4$ and $15{ }^{\circ} \mathrm{C}$ respectively. Antioxidant mechanisms, such as total antioxidant activity (TAS), superoxide dismutase (SOD) activity, and leaf morphological attributes with a putative protective role against UV-B were assessed. Finally, damaging effects of UV-B such as: malonaldialdehide (MDA) accumulation, maximum photochemical efficiency of the PSII and photoinactivation were assessed at each treatment. Both ecotypes showed reduced leaf area and thickening of leaf parenchyma. The Andean ecotype exhibited higher levels of TAS with high and medium UV-B radiation. The highest SOD activity was measured in the Andean ecotype. It was detected an increase of up to eight times of the basal level at four hours of radiation. The Antarctic ecotype exposed to UV-B and cold showed a higher damage in membranes 
(MDA), also a greater degree of photoinactivation. Additionally, the accumulation a new Cu- $\mathrm{Zn} / \mathrm{SOD}$ isoform, insensitive to $\mathrm{H}_{2} \mathrm{O}_{2}$ was detected in UV-B treated plants. In conclusion, the Andean ecotype presents a more effective antioxidant response against UV-B than the Antarctic ecotype.

Key words: Antarctic, antioxidants, oxidative damage, UV-B.

\section{INTRODUCCIÓN}

Los sitios de clima frío, tales como la Antártida Marítima y los Andes de Chile Central, presentan condiciones hostiles para el desarrollo de plantas vasculares dados los fuertes vientos, suelos pobres en materia orgánica, y elevados niveles de radiación fotosintéticamente activa (PAR) y ultravioleta-B (UV-B) (Robinson et al. 2003, Green et al. 2007). No obstante, las plantas que viven en esos sitios poseen diversos mecanismos morfológicos y fisiológicos que les permiten sobrevivir a las condiciones ambientales imperantes (Molina-Montenegro \& Cavieres 2010, Lütz 2010).

En los Andes de Chile Central (e.g., La Parva, $2600 \mathrm{msnm}, 33^{\circ} 19^{\prime} \mathrm{S}, 70^{\circ} 17^{\prime} \mathrm{W}$ ), durante la estación de crecimiento, es posible registrar radiación $\mathrm{PAR}$ con máximos diarios que superan los $2000 \mu$ moles $\mathrm{m}^{-2} \mathrm{~s}^{-1}$ (CasanovaKatny et al. 2006) y UV-B con máximos diarios promedios estimados sobre $60 \mu \mathrm{W}$ $\mathrm{cm}^{-2}$ (Cabrera et al. 1995) respectivamente. Las temperaturas mínimas en promedio oscilan entre 2 y $6{ }^{\circ} \mathrm{C}$ (Cavieres et al. 2007) y las precipitaciones anuales sobre los 2200 msnm. promedian entre 400 y 900 $\mathrm{mm}$, mayoritariamente en la forma de nieve durante el invierno (Santibáñez \& Uribe 1990). La Antártica Marítima (e.g., Isla Rey Jorge, $62^{\circ} 14^{\prime} \mathrm{S}, 58^{\circ} 42^{\prime} \mathrm{W}$ ) presenta una temperatura promedio de $1.6{ }^{\circ} \mathrm{C}$ en verano y precipitaciones anuales que promedian los 700 $\mathrm{mm}$, principalmente en la forma de nieve en invierno (Green et al. 2007). Durante el verano antártico, en días despejados la radiación PAR puede alcanzar con frecuencia los $1500 \mu \mathrm{mol}$ $\mathrm{m}^{-2} \mathrm{~s}^{-1}$, y ocasionalmente $\operatorname{los} 2000 \mu \mathrm{mol} \mathrm{m} \mathrm{m}^{-2} \mathrm{~s}^{-}$ 1 (Day et al. 2001), un fotoperiodo de hasta 21 horas de luz en enero y niveles de UV-B promedios de $5 \mu \mathrm{W} \mathrm{cm} \mathrm{cm}^{-2}$ al mediodía, los cuales han ido en aumento en las últimas décadas producto del adelgazamiento de la capa de ozono (Madronich et al. 1998, Day et al. 2001).
Cuando la temperatura ambiente es baja $\left(4{ }^{\circ} \mathrm{C}\right)$ y se inactivan las enzimas del ciclo de Calvin, se produce un desbalance energético entre la energía lumínica absorbida y la que el aparato fotosintético es capaz de utilizar, lo cual puede inducir un exceso de especies activas de Oxígeno (EAOs), daño fotooxidativo en el fotosistema II (PSII) y finalmente fotoinhibición (Huner et al. 1998, Keren \& Krieger-Liszkay 2011). Las EAOs son un subproducto inevitable del metabolismo aeróbico y su producción usualmente se incrementa por el estrés ambiental (Fryer et al. 2002, Zulfugarov et al. 2011). La magnitud del daño causado por las EAOs depende de su concentración basal en las células. Si se eleva la cantidad de EAOs, estas causan importantes daños al reaccionar con lípidos, proteínas y ácidos nucleicos, constituyendo la condición conocida como estrés oxidativo (Gill \& Tuteja 2010).

Por otro lado, el exceso de radiación UV-B afecta negativamente procesos fisiológicos como el crecimiento, fotosíntesis y respiración al dañar macromoléculas esenciales como ácidos nucleicos, proteínas y fosfolípidos (Jordan 1996, Jansen et al. 1998). El daño por UV-B, de manera similar a la fotoinhibición, transcurre en buena parte por intermedio de la acumulación de EAOs (Stapleton 1992, Mackerness et al. 2001), que pueden oxidar componentes como fosfolípidos de membranas, formando peróxidos como Malondialdehido (MDA) e inducir daño en cloroplastos y mitocondrias (Rozema et al. 1997); expresión disminuida de genes vinculados a la fotosíntesis (Musil 1996), inactivación de enzimas ligadas a la fotosíntesis (Teramura \& Sullivan 1994), daño a proteínas del PSII y pigmentos fotosintéticos (Shi et al. 2011) que llevan a una disminución de la eficiencia fotosintética del PSII (Fv/Fm) y fotoinactivación $(\mathrm{PhI})$.

Se ha documentado que la radiación UV-B induce cambios morfológicos y metabólicos que ayudan a la planta a contrarrestar sus efectos nocivos, tales como la acumulación de flavonoides y otros metabolitos que absorben 
UV-B en la epidermis (Fagerberg \& Bornman 2005), el aumento de las enzimas y compuestos antioxidantes que participan del ciclo HalliwellAsada, que pueden neutralizar el exceso de EAOs (Asada 1999), principalmente la Superóxido Dismutasa (SOD) (Jansen et al. 1998, Kataria 2007) en sus tres isoformas conocidas, las cuales se localizan y regulan diferencialmente según el tipo y magnitud de estrés oxidativo (Alscher et al. 2002, Kataria et al. 2007). También se han observado cambios morfológicos como la reducción del área foliar, el engrosamiento de parénquimas y mesófilo (Robberecht \& Caldwell 1983, Carrasco-Ríos 2009). Todos estos ajustes permiten a las plantas desarrollarse en ambientes con altos niveles de radiación UV-B.

Colobanthus quitensis (Kunth) Bartl. (Caryophyllaceae) es una dicotiledónea que habita desde el sur de México hasta los $68^{\circ} 42^{\prime}$ S en la Antártica Marítima (Moore 1970). Dado su amplio rango latitudinal de distribución y el aislamiento en que se han desarrollado diversas poblaciones de esta especie es que se han generado ecotipos adaptados a ambientes particulares (Gianoli et al. 2004, Sierra-Almeida et al. 2007, Molina-Montenegro et al. 2012). Por ejemplo, Gianoli et al. (2004), basándose en estudios de resistencia al congelamiento, morfología y secuenciación de regiones ITS establecieron que existe una marcada diferenciación ecotípica entre las poblaciones de la Cordillera de los Andes en Chile central y las poblaciones antárticas. El ecotipo Antártico es catalogado como resistente al frío (Bravo et al. 2001), puede mantener una tasa fotosintética positiva a $0{ }^{\circ} \mathrm{C}$ y un aumento en la actividad antioxidante cuando es expuesta a baja temperatura y alta intensidad lumínica (Xiong et al. 1999, Perez-Torres et al. 2004). El ecotipo Antártico también ha sido reportado como resistente a los crecientes niveles de radiación UV-B presentes en su hábitat, provocados por el adelgazamiento de la capa de ozono, mostrando cambios en la anatomía de las hojas, aumento de la concentración de carotenos junto con compuestos solubles que absorben en la región UV-B (280-320 nm) (Xiong et al. 1999a, Day et al. 2001). El ecotipo Andino, por su parte, ha sido menos estudiado. Durante su etapa de crecimiento enfrenta oscilaciones térmicas más amplias (entre 0 y $22{ }^{\circ} \mathrm{C}$ ) (Casanova-Katny et al. 2006). También se ha reportado que presenta capacidad de aclimatación al frío y un aumento de actividad Superóxido Dismutasa (SOD) en meses fríos y en condiciones fotoinhibitorias (Gianoli et al. 2004, Bravo et al. 2007).

A pesar de las adversas condiciones ambientales donde crece cada ecotipo, ninguno de ellos muestra síntomas evidentes de daño por radiación UV-B y baja temperatura. Recientemente Molina-Montenegro et al. (2012) demostraron que bajo condiciones hídricas limitantes, los individuos de $C$. quitensis podrían ajustar tanto el largo como el ancho foliar maximizando su desempeño fisiológico. De esta manera, se puede sugerir que los ajustes morfológicos foliares son una estrategia funcional en individuos de $C$. quitensis que permiten mantener un buen desempeño fisiológico bajo condiciones adversas. Si bien a la fecha existe información acerca de los mecanismos por los cuales los ecotipos de C. quitensis son capaces de sobrevivir exitosamente a la alta radiación PAR y baja temperatura, no se ha descrito de qué forma esta especie logra sobrellevar el estrés oxidativo inducido por alta radiación UV-B a la que se encuentran expuestas sus poblaciones naturales en la Cordillera de los Andes de Chile Central. De manera similar resulta interesante conocer la capacidad de las poblaciones antárticas para enfrentar niveles de radiación UV-B cada vez más elevados, debido al creciente adelgazamiento de la capa de ozono. Tampoco existe información si la baja temperatura potenciaría los efectos nocivos del UV-B, tal como ocurre con altos niveles de PAR en plantas. Si esto es así, entonces, dado que los ecotipos Antártico y Andino difieren en su resistencia a la baja temperatura es posible esperar que el efecto del UV-B sea dependiente de la temperatura y del ecotipo.

El objetivo de este trabajo es conocer los mecanismos fotoprotectores, tanto fisiológicos como morfológicos que han adoptado los ecotipos de C. quitensis, Antártico y Andino, a nivel de sus hojas para tolerar con éxito los efectos dañinos derivados de la alta radiación UV-B y baja temperatura. Específicamente evaluamos la magnitud del aumento en la actividad antioxidante enzimática y no enzimática (TAS, SOD), cambios morfoanatómicos foliares, indicadores de daño infligido a membranas biológicas (MDA) y capacidad de recuperar su desempeño 
fotosintético $(\mathrm{Fv} / \mathrm{Fm}, \mathrm{PhI})$, frente a altos niveles de radiación UV-B y baja temperatura. En el presente estudio proponemos que bajo condiciones controladas de laboratorio, los individuos de $C$. quitensis provenientes de la cordillera de Los Andes, donde los niveles de radiación UV-B son mayores que en la Antártica, tendrían un conjunto de mecanismos antioxidantes más eficaces para contrarrestar los efectos del UV-B, sufriendo menos daño que los del ecotipo Antártico.

\section{MÉTODOS}

\section{Cultivo de material vegetal}

Se usaron plantas de Colobanthus quitensis recolectadas en la Antártida (Isla Rey Jorge, 62 $2^{\circ} 14^{\prime}$ S, $58^{\circ} 42^{\prime}$ W) en febrero de 1997 y La Parva, Chile (33 ${ }^{\circ} 19^{\prime} \mathrm{S}, 70^{\circ} 16^{\prime} \mathrm{W}$, $2600 \mathrm{msnm}$ ) en marzo de 2001. Los especímenes se multiplicaron por separación de esquejes en bandejas plásticas de $18 \times 22 \mathrm{~cm}$ en una mezcla de tierra de hojas/turba (3:1). Las plantas se crecieron y propagaron en cámaras climatizadas a $15{ }^{\circ} \mathrm{C}$ con un fotoperíodo de $21 / 3 \mathrm{luz} / \mathrm{oscuridad}\left(150 \mu \mathrm{mol}\right.$ de fotones $\mathrm{m}^{-2}$ $\mathrm{s}^{-1}$ ) por aproximadamente seis años antes de iniciar los experimentos de UV-B. Las plantas se regaron periódicamente y fertilizaron con solución nutritiva Phostrogen $\left(0.2 \mathrm{mg} \mathrm{L}^{-1}\right)$.

\section{Exposición a frío $y / o$ radiación $U V-B$}

Bandejas de plantas con aproximadamente 50 individuos de $C$. quitensis cada una se colocaron en dos cámaras climáticas a 4 y $15{ }^{\circ} \mathrm{C}$ respectivamente, con fotoperíodo de $21 / 3 \mathrm{luz} / \mathrm{oscuridad}\left(150 \mu \mathrm{mol}\right.$ de fotones $\left.\mathrm{m}^{-2} \mathrm{~s}^{-1}\right)$, en presencia de radiación ultravioleta-B (UV-B) (280$320 \mathrm{~nm}$ ) de $3.0 \mu \mathrm{W} \mathrm{cm}{ }^{-2}, 35.0 \mu \mathrm{W} \mathrm{cm}-2$ y $70.0 \mu \mathrm{W} \mathrm{cm}{ }^{-2}$, proporcionada por tubos fluorescentes UV-B-313 de 40 W (Q-Panel, Cleveland, Ohio). Los tubos fueron cubiertos por filtros de Mylar (Du-Pont) para evitar la radiación de longitud de onda menor a $320 \mathrm{~nm}$. Las plantas que recibieron $3.0 \mu \mathrm{W} \mathrm{\textrm {cm } ^ { - 2 }}$ fueron consideradas como condición control, puesto que esta intensidad de radiación UV-B es la que proviene de los tubos fluorescentes normales en las cámaras de cultivo, los $35.0 \mu \mathrm{W} \mathrm{cm}-2$ y $70.0 \mu \mathrm{W} \mathrm{cm} \mathrm{cm}^{-2}$ se usaron como condiciones experimentales de mediana y alta intensidades, considerando el rango de radiación UV-B reportado en la literatura para La Parva. Se colectaron muestras de hojas cada 4 horas durante un ciclo de 24 horas expuestas a los diferentes niveles de radiación UV-B y se congelaron en nitrógeno líquido para su posterior análisis.

\section{Extracciones enzimáticas}

Se congelaron tallo y hojas en nitrógeno líquido y se homogenizaron en tubos Eppendorf con buffer fosfato $100 \mathrm{mM}$ (pH 7.8), 2 mM EDTA y 1 \% PVP (polyvinylpyrrolidone). El homogenizado se centrifugó a 14500 g x 10 min y se rescató el sobrenadante para las determinaciones.

\section{Antioxidantes hidrosolubles totales (TAS)}

Muestras de tallo y hojas $(0.1 \mathrm{~g})$ fueron homogeneizadas en tubos Eppendorf con nitrógeno liquido y extraídas con buffer fosfato $100 \mathrm{mM}$ (pH 7.4). El homogenizado se centrifugó a $14500 \mathrm{~g}$ y se reservó el sobrenadante para medir TAS. El método usado se basa en la habilidad de los antioxidantes solubles presentes para inhibir la oxidación del 2,2ç-azino-di-[3-etilbenzotiazolin sulfonato] (ABTS) a $\mathrm{ABTS}^{+}$por metmioglobina (Miller et al. 1993). La reacción se sigue en un espectrofotómetro a $600 \mathrm{~nm}$ (Calbiochem kit $\mathrm{n}^{\circ}$ 615700).

\section{Actividad superóxido dismutasa total}

La actividad SOD en el buffer de extracción se determinó de acuerdo al método descrito por McCord \& Fridovich (1969) y modificado por Schöner \& Krause (1990). Se siguió la taza de reducción de Ferrocitocromo $\mathrm{C}(\mathrm{Fc})$ a $550 \mathrm{~nm}$. Una unidad SOD se define como la cantidad de enzima necesaria para inhibir en un 50 \% la reducción del Fc en un sistema enzimático acoplado xantina-xantina oxidasa a pH 7.8 y $25{ }^{\circ} \mathrm{C}$.

\section{Isoformas de SOD}

Las isoenzimas SOD se determinaron de acuerdo a Rao et al. (1996). Cantidades iguales de SOD (1 U) fueron sometidas a electroforesis en geles nativos de poliacrilamida al $12 \%$ a $50 \mathrm{mV}$ por cinco horas a $4{ }^{\circ} \mathrm{C}$. La identificación de isoenzimas se realizó incubando los geles con $\mathrm{KCN} 3 \mathrm{mM}$ y $5 \mathrm{mM}$ de $\mathrm{H}_{2} \mathrm{O}_{2}$ por 30 min, antes de teñir con NBT $2.5 \mathrm{mM}$ por $25 \mathrm{~min}$, seguido por una incubación de $30 \mathrm{~min}$ en una solución de riboflavina 28 $\mu \mathrm{M}$, TEMED $28 \mathrm{mM}$ y fosfato de potasio ( $\mathrm{pH} 7.8$ ), todo en oscuridad. El revelado se lleva a cabo exponiendo los geles en un transiluminador con luz visible por $15 \mathrm{~min}$ a temperatura ambiente.

\section{Anatomía foliar}

Hojas de C. quitensis provenientes de la Antártida y Los Andes fueron colectadas después de tres meses de

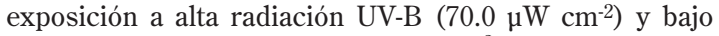
condiciones de control $(3.0 \mu \mathrm{W} \mathrm{cm}-2)$ en cámaras de cultivo. Las muestras foliares cortadas en fragmentos de 3-4 mm se fijaron en formaldehído con alcohol-ácido por 48 horas, y posteriormente depositadas en una batería de alcoholes de grado ascendente (hasta $100 \%$ ) y por 10 horas en terbutanol. Cuando las muestras estuvieron deshidratadas se procedió a su inclusión en paraplast, corte con micrótomo y tinción con Fast-Green. Todas las muestras fueron observadas y analizadas a través de un microscopio óptico confocal (Carl Zeiss, Axio CSM 700). En tres cortes transversales de hojas de cinco individuos de C. quitensis provenientes de ambos orígenes y sometidos a alta radiación UV-B y control, se midió el grosor del mesófilo, el espesor del parénquima esponjoso y de empalizada. Adicionalmente, mediante un calibre digital (Mitutoyo $0.001 \mathrm{~mm}$ ) se midió el largo y ancho foliar en tres hojas de los mismos cinco individuos utilizados para las mediciones tisulares.

\section{Peroxidación de lípidos}

Se midió contenido de Malondialdehido (MDA) por el método basado en la reacción con Acido Tiobarbitúrico (Dhindsa et al. 1982). MDA es un indicador de la peroxidación de lípidos que daña membranas biológicas. Se homogenizó $0.1 \mathrm{~g}$ de tejido foliar en $2 \mathrm{ml}$ de TCA $0.1 \%$ (p/v) y se centrifugó el extracto a 12000 g. El sobrenadante fue tratado con $400 \mu \mathrm{l}$ de TCA $20 \%$ y 0.5 $\%$ de ácido tiobarbitúrico. Se calentó la mezcla a $95{ }^{\circ} \mathrm{C}$ por 30 min y se enfrió en hielo. El contenido de MDA se determinó midiendo la absorbancia a $586 \mathrm{~nm}$. 
Determinación de la eficiencia fotoquímica del PSII $e$ indice de fotoinactivación (Phi)

Se midió el cambio en la eficiencia fotoquímica del PSII mediante un fluorímetro modulado FMS2 (Hansatech) a través de la razón $\mathrm{F}_{\mathrm{v}} / \mathrm{F}_{\mathrm{m}}$. Se usaron hojas previamente adaptadas a oscuridad por un periodo de 30 minutos a las cuales se les aplicó un pulso de luz saturante de 9000 $\mu \mathrm{mol} \mathrm{m} \mathrm{m}^{-2} \mathrm{~s}^{-1}$ durante $0.8 \mathrm{~s}$.

El índice de fotoinactivación (Phi) se calculó según la fórmula: $\mathrm{Phi}=1-\left(\mathrm{F}_{\mathrm{v}} / \mathrm{F}_{\mathrm{m}}\right)_{\mathrm{exp}} /\left(\mathrm{F}_{\mathrm{v}} / \mathrm{F}_{\mathrm{m}}\right)_{\text {ctr }}$ donde $\left(\mathrm{F}_{\mathrm{v}} / \mathrm{F}_{\mathrm{m}}\right)$ exp es la eficiencia fotoquímica del PSII en condiciones experimentales y $\left(\mathrm{F}_{\mathrm{v}} / \mathrm{F}_{\mathrm{m}}\right)_{\mathrm{ctr}}$ corresponde a los controles respectivos (Larcher 2000).

\section{Análisis estadísticos}

Los diferentes atributos morfológicos foliares fueron comparados mediante una análisis de varianza (ANOVA) de dos vías, donde el origen (Antártico y Andino) y la intensidad de la radiación UV-B $\left(3,35\right.$ y $\left.70 \mu \mathrm{W} \mathrm{cm}^{-2}\right)$ fueron las variables independientes (Zar 1999). Las variables fisiológicas y bioquímicas (actividad SOD total, TAS, MDA y Fv/Fm) fueron comparadas a través de un ANOVA de tres vías de mediciones repetidas a las $0,12 \mathrm{y}$ 24 horas del tratamiento.

Los factores fueron origen (Antártico y Andino), temperatura $\left(4\right.$ y $\left.15{ }^{\circ} \mathrm{C}\right)$, radiación UV-B $(3,35$ y $70 \mu \mathrm{W}$ $\mathrm{cm}^{-2}$ ). Cuando se registraron diferencias significativas en los diferentes factores se realizó un test para comparaciones múltiples (Fisher-LSD). Previamente se evaluó la normalidad de los datos y la homogeneidad de la varianza mediante los test Shapiro-Wilks y Bartlett, respectivamente (Sokal \& Rohlf 1995). Todos los análisis fueron realizados con el software Statistica 6.0.

\section{RESULTADOS}

\section{Antioxidantes solubles totales (TAS)}

El ecotipo Andino presentó significativamente mayores niveles en el contenido de antioxidantes solubles totales (TAS) que el ecotipo Antártico $\left(\mathrm{F}_{1.24}=13728.6 ; \mathrm{P}<0.0001\right)$. Como resultado de la exposición a radiación UV-B a $15{ }^{\circ} \mathrm{C}$ (Fig. 1B), en el ecotipo Antártico se apreció una baja de TAS de $20 \%$ para la intensidad media y de un $40 \%$ para la intensidad alta a $15{ }^{\circ} \mathrm{C}$ (Fisher-LSD, Fig. 1A). Para $4{ }^{\circ} \mathrm{C}$ la disminución en el ecotipo Antártico fue de $40 \%$ para la intensidad media y de $60 \%$ para
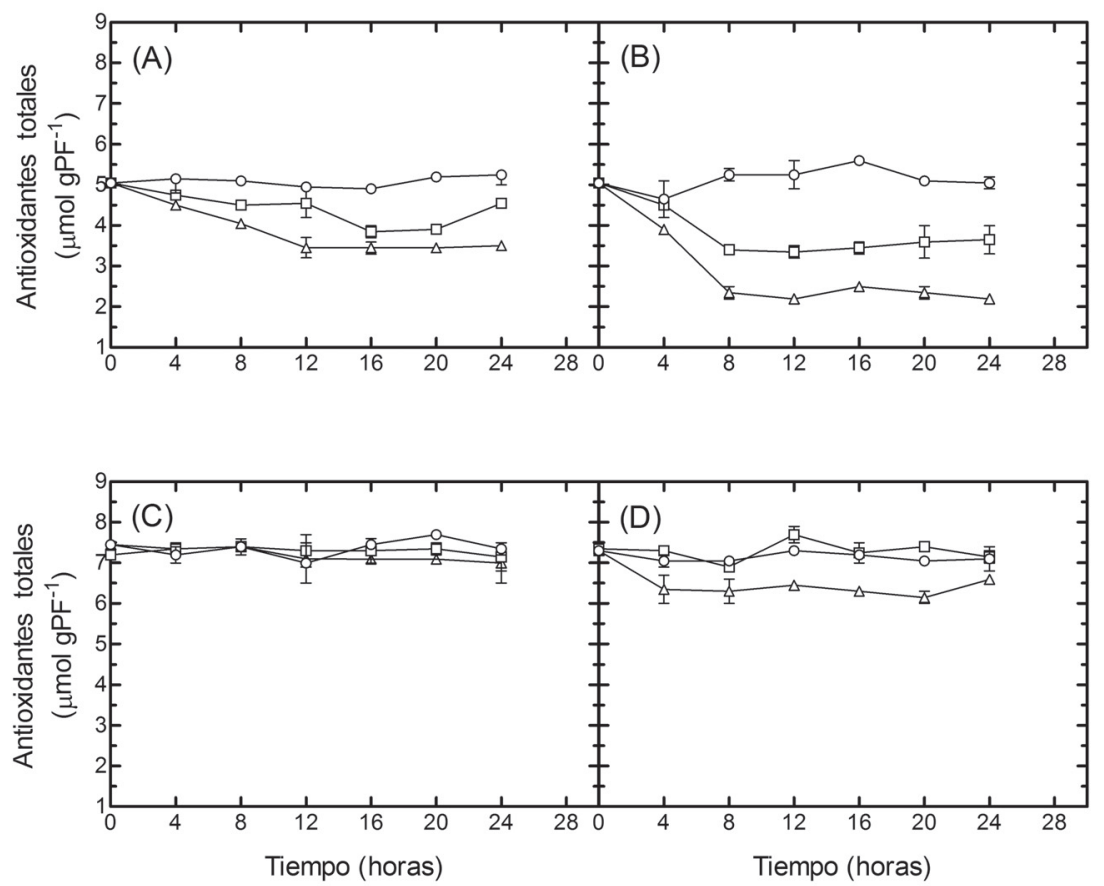

Fig. 1: Antioxidantes solubles totales (TAS) en hojas de Colobanthus quitensis. Las plantas se expusieron a tres intensidades de UV-B durante 24 horas. -O- plantas control $\left.(3.0 \mu \mathrm{W} \mathrm{cm})^{-2}\right)$; - - - UV-B $\left(35.0 \mu \mathrm{W} \mathrm{cm}{ }^{-2}\right)$; - $\Delta$ - UV-B $(70.0$ $\mu \mathrm{W} \mathrm{cm}-2$. (A) Ecotipo Antártico a $15^{\circ} \mathrm{C}$ y (B) $4{ }^{\circ} \mathrm{C}$, (C) ecotipo Andino a $15{ }^{\circ} \mathrm{C}$ y a (D) $4{ }^{\circ} \mathrm{C} . \mathrm{n}=3$

Total soluble antioxidants (TAS) in Colobanthus quitensis leaves. Plants were exposed to three intensities of UV-B for 24 hours -O- control plants $(3.0 \mu \mathrm{W} \mathrm{cm}-2)$; - $\square$ - UV-B $(35.0 \mu \mathrm{W} \mathrm{cm}-2)$; - $\Delta$ - UV-B $(70.0 \mu \mathrm{W} \mathrm{cm}-2)$. (A) Antarctic ecotype at $15{ }^{\circ} \mathrm{C}$ and (B) $4{ }^{\circ} \mathrm{C}$, (C) Andean ecotype at $15{ }^{\circ} \mathrm{C}$ and (D) $4{ }^{\circ} \mathrm{C} . \mathrm{n}=3$. 
intensidad alta (Fisher-LSD, Fig. 1C). Para ambas temperaturas, la menor concentración de TAS se alcanzó cerca de las nueve horas y se mantuvo hasta el final del tratamiento $\left(\mathrm{F}_{3.72}=26.0 ; \mathrm{P}<0.001\right.$; ver Fisher-LSD $)$. En el ecotipo Andino no se observaron diferencias significativas entre tratamientos con UV-B a 4 ${ }^{\circ} \mathrm{C}$ ni a $15{ }^{\circ} \mathrm{C}\left(\mathrm{F}_{1.24}=1.0 ; \mathrm{P}=0.32\right.$; Fig. 1-B y $\left.\mathrm{D}\right)$.

\section{Actividad e isoformas de SOD}

La exposición a intensidades de UV-B media y alta indujo aumentos significativos de la actividad SOD en todos los tratamientos $\left(\mathrm{F}_{2.24}\right.$ $=1287.4 ; \mathrm{P}<0.001)$. En el ecotipo Antártico se produjo un aumento de actividad SOD hasta cinco veces con respecto al nivel basal. El máximo se alcanzó a las nueve horas de tratamiento para ambas temperaturas para después descender paulatinamente hacia el final del tratamiento a dos veces el nivel basal (Fisher-LSD; Figs. 2A y 2C). El ecotipo Andino, en cambio, presentó su máximo a las seis horas de tratamiento para intensidad UV-B media y alta a $4{ }^{\circ} \mathrm{C}$ y $15{ }^{\circ} \mathrm{C}$, con una actividad similar a la del ecotipo Antártico (Fisher-LSD; Figs. 2B y 2D). También se observó que los niveles basales en ambos ecotipos fueron significativamente mayores a $4{ }^{\circ} \mathrm{C}$ que a $15{ }^{\circ} \mathrm{C}$ para ambos ecotipos $\left(\mathrm{F}_{1.24}=136.6 ; \mathrm{P}<0.001\right.$; Fig. 2).

Ambos ecotipos tratados a $3.0 \mu \mathrm{W} \mathrm{cm} \mathrm{cm}^{-2}$ a $15{ }^{\circ} \mathrm{C}$ y $4{ }^{\circ} \mathrm{C}$ presentaron dos isoenzimas SOD: una Mn-SOD y una Fe-SOD (Fig. 3A y 3B). El ecotipo Andino expuesto a alta intensidad UV-B mantuvo este perfil. Sin embargo, el ecotipo Antártico expuesto a alta intensidad de radiación UV-B mostró una nueva isoenzima, identificada como $\mathrm{Cu} / \mathrm{Zn}-\mathrm{SOD}$ (Figs. 3A y 3B).

\section{Anatomía foliar}

Los individuos de C. quitensis expuestos a altas intensidades de radiación UV-B presentaron hojas de menor longitud en comparación a aquellos expuestos al
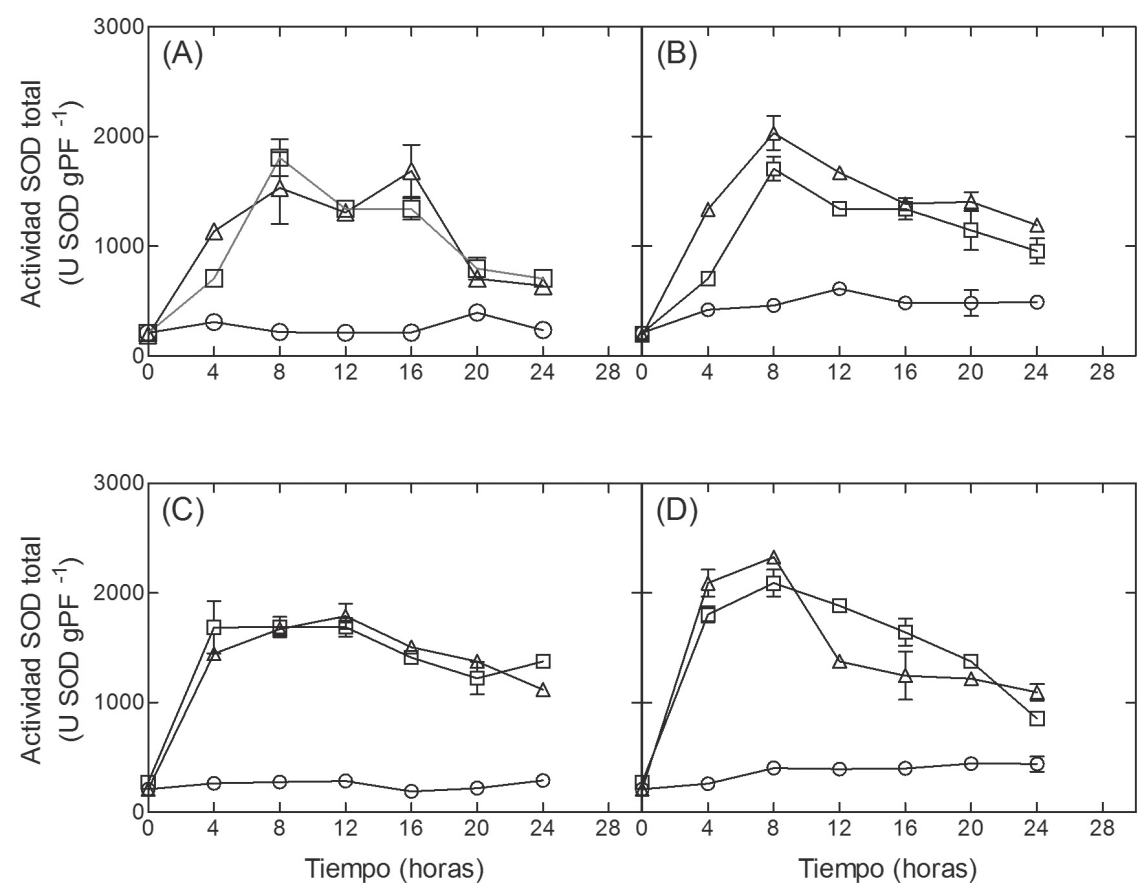

Fig. 2: Actividad Superóxido Dismutasa (SOD) en hojas de Colobanthus quitensis. Las plantas se expusieron a tres intensidades de UV-B durante 24 horas. - $\square$ - plantas control $\left(3.0 \mu \mathrm{W} \mathrm{cm}\right.$ cm $^{-2}$; - $\square$ - UV-B $\left(35.0 \mu \mathrm{W} \mathrm{cm}{ }^{-2}\right)$; - $\square-$ UV-B $\left(70.0 \mu \mathrm{W} \mathrm{cm}{ }^{-2}\right)$. (A) Ecotipo Antártico a $15^{\circ} \mathrm{C}$ y (B) $4{ }^{\circ} \mathrm{C}$, (C) ecotipo Andino a $15^{\circ} \mathrm{C}$ y a (D) $4{ }^{\circ} \mathrm{C} . \mathrm{n}=3$.

Total Superoxide Dismutase (SOD) activity in Colobanthus quitensis leaves. Plants were exposed to three intensities of UV-B for 24 - $\square$ - control plants $(3.0 \mu \mathrm{W} \mathrm{cm}-2)$; - $\square-$ UV-B $(35.0 \mu \mathrm{W} \mathrm{cm}-2)$; - $\square$ - UV-B $\left(70.0 \mu \mathrm{W} \mathrm{cm}{ }^{-2}\right)$. (A) Antarctic ecotype at $15{ }^{\circ} \mathrm{C}$ and (B) 4 ${ }^{\circ} \mathrm{C}$, (C) Andean ecotype at $15{ }^{\circ} \mathrm{C}$ and (D) $4{ }^{\circ} \mathrm{C} . \mathrm{n}=3$. 
tratamiento control (Tablas 1 y 2). Por otro lado, aquellos individuos provenientes de Los Andes presentaron hojas de mayor longitud en comparación a aquellos provenientes de la Antártica (Tablas 1 y 2). De manera similar, el ancho foliar también fue afectado significativamente bajo la exposición a radiación UV-B en individuos de $C$. quitensis de ambos orígenes, siendo aquellos provenientes de Los Andes los que presentaron la mayor reducción del ancho foliar (Tablas 1 y 2).

El espesor del mesófilo fue significativamente mayor en aquellos individuos de $C$. quitensis provenientes de la Antártica en comparación a aquellos de Los Andes (Tablas 1 y 2). Por otro lado el espesor del mesófilo aumentó de manera significativa en los individuos de $C$. quitensis que fueron expuestos a altas intensidades de radiación UV-B en comparación a los controles (Tabla 1). El grosor del parénquima esponjoso fue significativamente mayor en los individuos provenientes de la Antártica que en aquellos provenientes de Los Andes (Tablas 1 y 2). Adicionalmente, la exposición a altas intensidades de radiación UV-B indujo un aumento significativo en el grosor del parénquima esponjoso en comparación al control (Tablas 1 y 2). El grosor del parénquima de empalizada fue significativamente mayor en aquellos individuos provenientes de la Antártica en comparación a sus coespecíficos provenientes de Los Andes (Tablas 1 y 2). Por otro lado, el tratamiento de radiación UV-B no afectó el grosor del parénquima de empalizada en comparación al control (Tablas 1 y 2).

\section{Peroxidación de lípidos (MDA)}

$\mathrm{El}$ ecotipo Antártico a $15{ }^{\circ} \mathrm{C}$ mostró un aumento sostenido en los niveles de malondialdehído (MDA) para los tratamientos con radiación UV-B media y alta, alcanzando 3.8 veces el nivel basal hacia el final del tratamiento con intensidad alta y 3.5 veces para intensidad media $\left(\mathrm{F}_{6.24}=7.31 ; \mathrm{P}<0.001 ;\right.$ Fig. $\left.4 \mathrm{~A}\right) . \mathrm{El}$ ecotipo Andino mostró un aumento similar de MDA a intensidades media y alta con respecto al control alcanzando niveles dos veces mayores a los basales que se sostienen a lo largo del experimento sin mostrar diferencias significativas entre intensidades de radiación $\left(\mathrm{F}_{2.24}=3.53 ; \mathrm{P}<0.005\right.$; Fig. $\left.4 \mathrm{~B}\right) . \mathrm{A} 4{ }^{\circ} \mathrm{C}$ el ecotipo Antártico mostró un aumento de alrededor de dos veces el nivel basal, sin mostrar diferencias significativas entre las

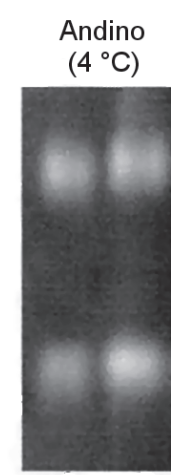

C

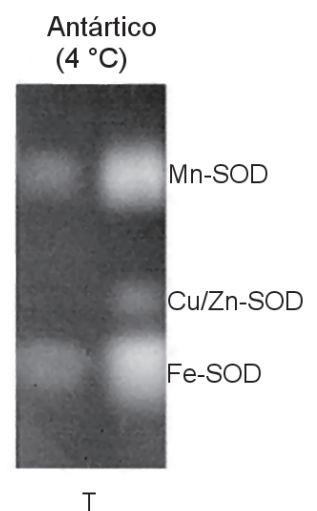

T

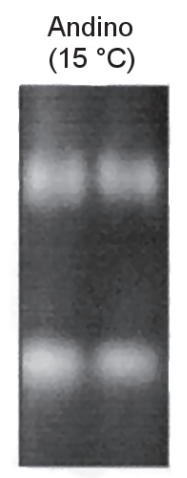

C

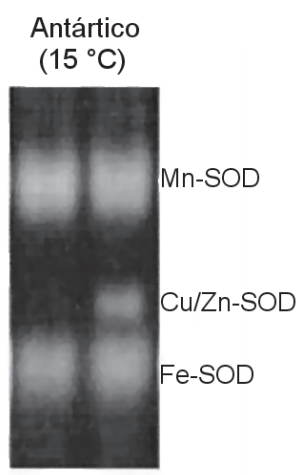

$\mathrm{T}$

Fig. 3: Patrones de isoenzimas de Superóxido Dismutasa (SOD) en hojas de Colobanthus quitensis. Las plantas se expusieron a $70(\mu \mathrm{W} \mathrm{cm}-2)$ durante 24 horas. Las bandas blancas corresponden a las isoenzimas SOD que fueron identificadas por ensayos de inhibición específicos con $\mathrm{KCN} \mathrm{y} \mathrm{H}_{2} \mathrm{O}_{2}$. Cada carril fue cargado con una unidad de SOD en cada carril. La electroforesis fue realizada en un gel nativo de poliacrilamida al $12 \%$ y corrida por 6 horas a $4{ }^{\circ} \mathrm{C}$. (C) Plantas controles sin UV-B, (T) plantas irradiadas $70 \mu \mathrm{W} \mathrm{cm}-2$.

Superoxide dismutase isozyme pattern in Colobanthus quitensis leaves. Plants were exposed to $\left(70.0 \mu \mathrm{W} \mathrm{cm}^{-2}\right)$ for $24 \mathrm{hours}$ White bands correspond to SOD isozymes that were identified by specific inhibition assays with KCN and hydrogen peroxide; one unit of SOD was loaded in each lane. Electrophoresis was performed in a $12 \%$ native polyacrylamide gel for 6 h at $4{ }^{\circ} \mathrm{C}$. (C) control plants without UV-B and (T) plants exposed to $70 \mu \mathrm{W} \mathrm{cm}^{-2}$. 
TABLA 1

Variación en la anatomía foliar $( \pm \mathrm{DE})$ de Colobanthus quitensis provenientes de la Antártica y Los Andes, expuestos durante tres meses a radiación UV-B $\left(70.0 \mu \mathrm{W} \mathrm{cm}{ }^{-2}\right)$ y condición control.

Variation in leaf anatomy $( \pm \mathrm{SD})$ of Colobanthus quitensis from Antarctic and Los Andes, exposed during three months to UV-B radiation $(70.0 \mu \mathrm{W} \mathrm{cm}-2)$ and control conditions.

\begin{tabular}{lcccc}
\hline & Antártico UV-B & $\begin{array}{c}\text { Antártico } \\
\text { Control }\end{array}$ & Andino UV-B & Andino Control \\
\hline Ancho foliar $(\mathrm{mm})$ & $1.002 \pm 0.04$ & $1.302 \pm 0.1$ & $0.868 \pm 0.09$ & $1.012 \pm 0.04$ \\
Largo foliar $(\mathrm{mm})$ & $8.575 \pm 0.6$ & $13.675 \pm 1.1$ & $13.55 \pm 1.4$ & $19.55 \pm 0.7$ \\
Grosor mesófilo $(\mu \mathrm{m})$ & $496.8 \pm 10.1$ & $455 \pm 20.3$ & $414.2 \pm 13.6$ & $395.6 \pm 11.8$ \\
Parénquima esponjoso $(\mu \mathrm{m})$ & $321.2 \pm 5.2$ & $299.6 \pm 9.3$ & $247.8 \pm 9.7$ & $229.8 \pm 10.5$ \\
Grosor Parénquima $(\mu \mathrm{m})$ & $194 \pm 8.0$ & $186 \pm 5.7$ & $162.4 \pm 10.5$ & $153.6 \pm 16.5$ \\
\hline
\end{tabular}

TABLA 2

Análisis estadístico de la variación de la anatomía foliar en Colobanthus quitensis provenientes de la Antártica y Los Andes, expuestos a radiación UV-B y condición control.

Statistical analysis of the variation in leaf anatomy in Colobanthus quitensis individuals from Antarctic and Los Andes origins exposed to UV-B radiation and control conditions.

\begin{tabular}{|c|c|c|c|}
\hline Atributo & g. 1. & $\mathrm{~F}$ & $\mathrm{P}$ \\
\hline \multicolumn{4}{|l|}{ Largo foliar (mm) } \\
\hline Origen $(\mathrm{O})$ & 1,16 & 120.3 & 0.001 \\
\hline Tratamiento $(\mathrm{T})$ & 1,16 & 132.3 & 0.001 \\
\hline $\mathrm{O} \times \mathrm{T}$ & 1,16 & 0.01 & 0.903 \\
\hline \multicolumn{4}{|c|}{ Ancho foliar (mm) } \\
\hline Origen $(\mathrm{O})$ & 1,16 & 39.9 & 0.001 \\
\hline Tratamiento $(\mathrm{T})$ & 1,16 & 43.7 & 0.001 \\
\hline $\mathrm{O} \times \mathrm{T}$ & 1,16 & 5.4 & 0.003 \\
\hline \multicolumn{4}{|c|}{ Grosor mesófilo ( $\mu \mathrm{m})$} \\
\hline Origen $(\mathrm{O})$ & 1,16 & 119.6 & 0.001 \\
\hline Tratamiento $(\mathrm{T})$ & 1,16 & 21.6 & 0.001 \\
\hline $\mathrm{O} \times \mathrm{T}$ & 1,16 & 3.2 & 0.092 \\
\hline \multicolumn{4}{|c|}{ Parénquima esponjoso ( $\mu \mathrm{m})$} \\
\hline Origen $(\mathrm{O})$ & 1,16 & 317.5 & 0.001 \\
\hline Tratamiento $(\mathrm{T})$ & 1,16 & 24.3 & 0.001 \\
\hline $\mathrm{O} \times \mathrm{T}$ & 1,16 & 0.20 & 0.660 \\
\hline \multicolumn{4}{|c|}{ Grosor Parénquima $(\mu \mathrm{m})$} \\
\hline Origen $(\mathrm{O})$ & 1,16 & 42.5 & 0.001 \\
\hline Tratamiento $(\mathrm{T})$ & 1,16 & 2.9 & 0.106 \\
\hline $\mathrm{O} \times \mathrm{T}$ & 1,16 & 0.01 & 0.936 \\
\hline
\end{tabular}



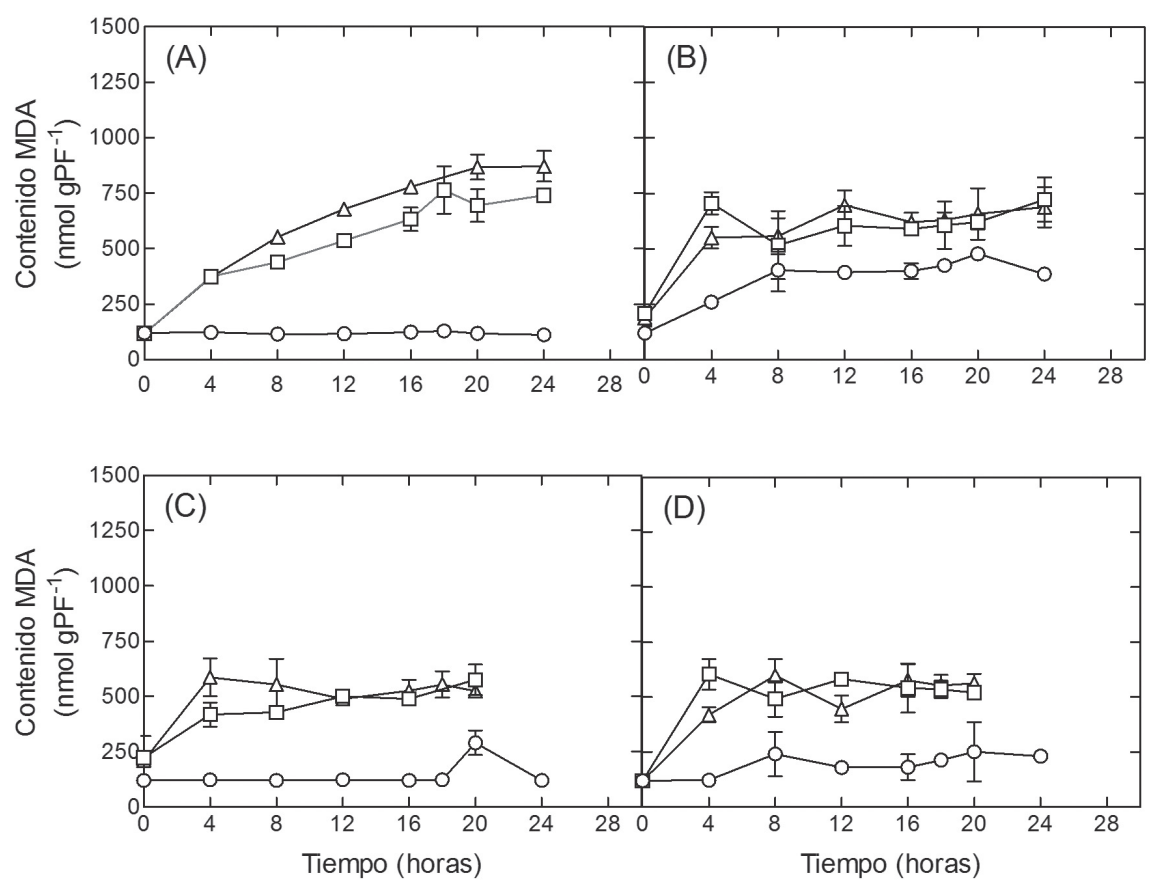

Fig. 4: Malondialdehido (MDA) en hojas de Colobanthus quitensis. Las plantas se expusieron a tres intensidades de UV-B durante 24 horas. -O- plantas control $(3.0 \mu \mathrm{W} \mathrm{cm}-2)$; $-\square-$ UV-B $(35.0 \mu \mathrm{W} \mathrm{cm}-2)$; - $\Delta$ - UV-B $\left(70.0 \mu \mathrm{W} \mathrm{cm}{ }^{-2}\right)$. (A) Ecotipo Antártico a $15{ }^{\circ} \mathrm{C}$ y (B) $4{ }^{\circ} \mathrm{C}$, (C) ecotipo Andino a $15{ }^{\circ} \mathrm{C}$ y (D) $4{ }^{\circ} \mathrm{C} . \mathrm{n}=3$.

Malondialdehyde (MDA) in Colobanthus quitensis leaves. Plants were exposed to three intensities of UV-B for 24 -O- control plants $\left(3.0 \mu \mathrm{W} \mathrm{cm}{ }^{-2}\right)$; - $\square$ - UV-B $(35.0 \mu \mathrm{W} \mathrm{cm}-2)$; - $\Delta$ - UV-B $(70.0 \mu \mathrm{W} \mathrm{cm}-2)$. (A) Antarctic ecotype at $15{ }^{\circ} \mathrm{C}$ and (B) $4{ }^{\circ} \mathrm{C}$, (C) Andean ecotype at $15^{\circ} \mathrm{C}$ and (D) $4{ }^{\circ} \mathrm{C} . \mathrm{n}=3$.

respuesta a radiación UV-B de mediana y alta intensidad $\left(\mathrm{F}_{2.24}=3.53 ; \mathrm{P}<0.005\right.$; Fig. $\left.4 \mathrm{~A}\right)$. Para los ensayos a $4{ }^{\circ} \mathrm{C}$ también se observó un incremento significativo en los niveles de MDA para los controles sin UV-B en el ecotipo Antártico $\left(\mathrm{F}_{1.24}=12.96\right.$; $\mathrm{P}<0.005$; Fig. 4-A y C $)$.

\section{Eficiencia fotoquímica del PSII (Fv/Fm) e indice de fotoinactivación (Phi)}

C. quitensis sometida a intensidad de radiación UV-B media y alta reportó un descenso del parámetro $\mathrm{Fv} / \mathrm{Fm}$ en ambos ecotipos a 4 ${ }^{\circ} \mathrm{C}$. En el ecotipo Antártico la disminución de Fv/Fm fue de un $10 \%$ y $18 \%$ para las intensidades media y alta, alcanzando este valor a las 36 horas de radiación continua (Fig. 5A). Pasadas 12 horas, en ausencia de radiación UV-B, se recuperó el 100 \% de la eficiencia fotoquímica. En el ecotipo Andino hubo una leve disminución de Fv/Fm que alcanzó el 8\% del valor inicial a las 36 horas en las plantas tratadas con UV-B de alta intensidad (Fig. 5B). A mediana intensidad de radiación UV-B se mostró una baja de $3 \%$ que permaneció constante desde las 18 horas. Después de 12 horas en ausencia de radiación UV-B se recuperaron los niveles iniciales de eficiencia fotoquímica del PSII en todas las plantas tratadas.

Al comparar los índices de fotoinactivación (Phi) de ambos ecotipos a intensidad media y alta de UV-B a $4{ }^{\circ} \mathrm{C}$ se observó que el ecotipo antártico tratado con UV-B de alta intensidad es el único que se fotoinactivó significativamente. La fotoinactivación del ecotipo Andino es similar en los dos tratamientos (Fig. 6).

\section{DISCUSIÓN}

El ecotipo Andino presentó mayores niveles de antioxidantes solubles totales (TAS) siendo 


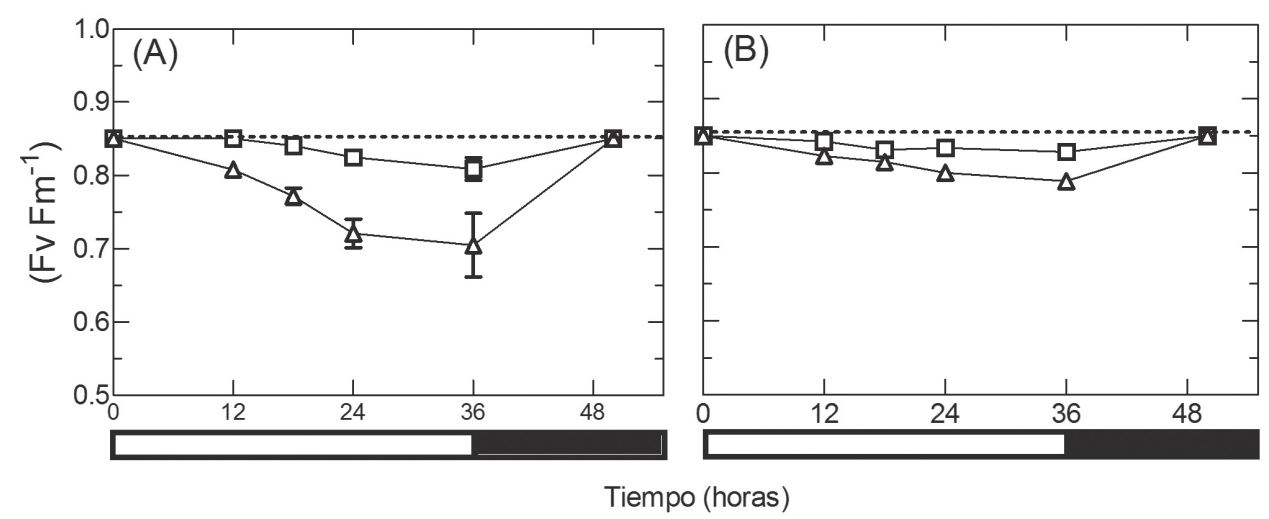

Fig. 5: Eficiencia fotoquímica del PSII (Fv/Fm) en hojas de Colobanthus quitensis. Las plantas se expusieron a dos intensidades de UV-B durante 36 horas seguidas de 12 horas de recuperación. - $\square-\mathrm{UV}-\mathrm{B}\left(35.0 \mu \mathrm{W} \mathrm{cm}^{-2}\right)$; $-\Delta$ UV-B $(70.0 \mu \mathrm{W} \mathrm{cm}-2)$. (A) Ecotipo Antártico a $4{ }^{\circ} \mathrm{C}$, (B) ecotipo Andino a $4{ }^{\circ} \mathrm{C} . \mathrm{n}=3$.

PSII photochemical efficiency (Fv/Fm) in Colobanthus quitensis leaves. Plants were exposed to two intensities of UV-B for 24 hours followed by 12 hours of recovery. - $\square$ - UV-B $\left(\mathrm{r} 35.0 \mu \mathrm{W} \mathrm{cm}{ }^{-2}\right)$; - $\Delta$ - UV-B $\left(70.0 \mu \mathrm{W} \mathrm{cm}{ }^{-2}\right)$. (A) Antarctic ecotype at $4{ }^{\circ} \mathrm{C}$, (B) Andean ecotype at $4{ }^{\circ} \mathrm{C} . \mathrm{n}=3$.

capaz de mantenerlos constantes durante los tratamientos con radiación UV-B media y alta, mientras que el ecotipo Antártico bajó hasta $60 \%$ su contenido de antioxidantes (Fig. 1). Este descenso probablemente se relaciona con un mayor nivel de radicales libres inducidos a alta UV-B, los cuales oxidan en mayor proporción el contenido de antioxidantes solubles. Estos resultados sugerirían que el ecotipo Andino presenta una mayor capacidad de mantener su homeostasis redox y/o una mayor tasa de recambio en sus mecanismos antioxidantes que el ecotipo Antártico frente a la radiación UV-B. Estudios en ambos ecotipos frente a otros factores ambientales generadores de estrés oxidativo muestran que los niveles de TAS se mantienen elevados o decaen levemente confirmando la capacidad de esta especie para mantener una elevada capacidad antioxidante (Perez-Torres et al. 2004). El efecto de la temperatura sobre la respuesta antioxidante total al UV-B se observa en forma similar para ambos ecotipos. La baja temperatura disminuye la capacidad antioxidante en los tratamientos más severos de UV-B en ambos ecotipos (Fig. 1). Este resultado es consistente con la fotoinactivación del PSII observada solo a baja temperatura (Fig. 5).

La exposición de C. quitensis por 24 horas a alta y mediana intensidad UV-B generó aumentos significativos y transitorios de la actividad SOD, los cuales terminan por estabilizarse hacia el final de los tratamientos en aproximadamente el doble de los valores basales. Cabe destacar que SOD en el ecotipo Andino alcanza su máximo en seis horas, comparados con las 48 horas de A. thaliana (Rao et al. 1996). Esto sugiere que el ecotipo Andino está particularmente capacitado para responder con su maquinaria enzimática con rapidez frente al incremento de radiación UV-B.

En C. quitensis se ha descrito tres isoformas de SOD, dos Fe-SOD y una MnSOD (PérezTorres et al. 2004). El estudio de expresión de isoformas de SOD en este trabajo arrojó la aparición de $\mathrm{Cu} / \mathrm{Zn}-\mathrm{SOD}$ en el ecotipo Antártico. Esta isoforma no había sido detectada anteriormente en los ecotipos de C. quitensis cuando fueron sometido a alta intensidad lumínica y aclimatación al frío (Vera 2003, Pérez-Torres et al. 2004) por lo que su aparición es atribuible a una respuesta inducida específicamente por el UV-B. Cabe notar que las isoformas de SOD están asociadas con organelos específicos: Mn-SOD con la mitocondria, la Fe-SOD con el cloroplasto y $\mathrm{Cu}$ / Zn-SOD con apoplasto, citosol y cloroplastos (Tsang et al. 1991, Karpinska et al. 2001, Radyukina et al. 2011). Existe evidencia de la expresión diferencial de las distintas isoformas SOD según la fuente de estrés oxidativo (Alscher et al. 2002, Kataria et al. 2007) y la isoforma $\mathrm{Cu} / \mathrm{Zn}$-SOD ha sido anteriormente reportada como inducible por UV-B en Lemma 


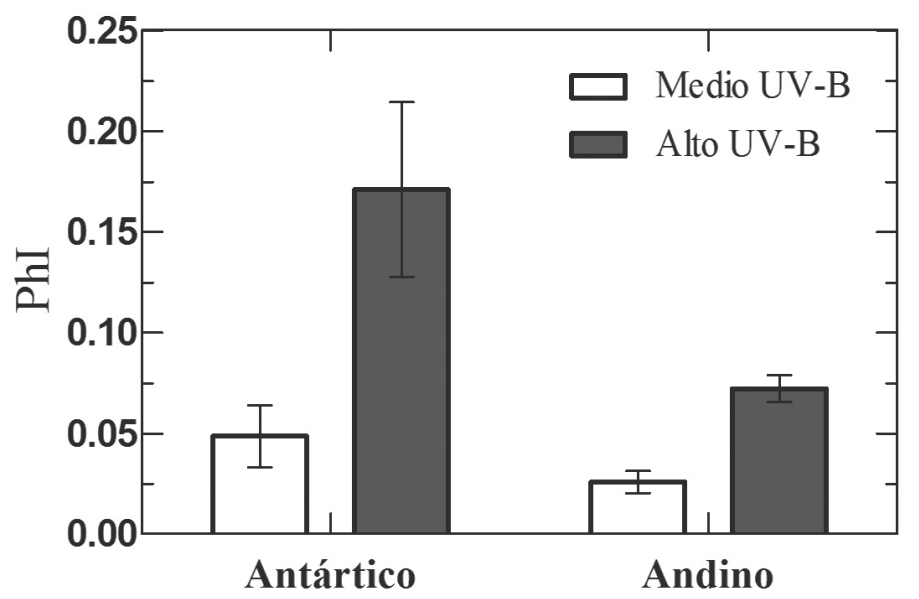

Fig. 6: Variación en el decaimiento fotosintético (Phi) en hojas de Colobanthus quitensis a $4{ }^{\circ} \mathrm{C}$. Se expusieron dos grupos de cada ecotipo a dos diferentes intensidades de UV-B. (UV Medio) plantas tratadas con mediana intensidad de UV-B $(35.0 \mu \mathrm{W} \mathrm{cm}-2)$; (UV Alto) plantas tratadas con alta intensidad de UV-B $\left(70.0 \mu \mathrm{W} \mathrm{cm}{ }^{-2}\right)$. Cada barra representa la media de tres mediciones y las barras de error al EE.

Photosynthetic decline (Phi) in Colobanthus quitensis leaves. Two ecotypes were exposed to two different plant UV-B intensities. (UV Medio) Plants treated with medium intensity of UV-B $\left(35.0 \mu \mathrm{W} \mathrm{cm}{ }^{-2}\right.$ ), (UV Alto) plants treated with high intensity UV-B $\left(70.0 \mu \mathrm{W} \mathrm{cm}{ }^{-2}\right)$. Each bar represents the mean of three measurements and the error bars to the SE.

gibba y A. thaliana (Rao et al. 1996, Babu et al. 2003). La expresión diferencial de $\mathrm{Cu} / \mathrm{Zn}-\mathrm{SOD}$ sería consistente con su papel como defensa frente a la radiación UV-B, puesto que permite responder a la generación de EAOs de manera ubicua y no solo en los organelos asociados a la fotosíntesis y respiración.

Es destacable que el descenso de la actividad SOD con el tiempo de exposición es por un lado consistente con el posible aumento de especies reactivas y con ello disminución del contenido de antioxidantes solubles. Sin embargo, parece inconsistente encontrar una mayor actividad SOD en el ecotipo Antártico. Esto posiblemente se explica por la mayor proporción de Fe-SOD presente en el ecotipo Andino (Fig. 3). Esta isoforma presenta mayor sensibilidad a peróxido de hidrógeno (Rao et al. 1996), una forma reactiva del oxígeno comúnmente acumulada en plantas expuestas a altos niveles de UV-B a nivel de hojas y en diversos tipos celulares (Wang et al. 2010, Fedina et al. 2010). Por lo tanto, la presencia de una $\mathrm{Cu} / \mathrm{Zn}$-SOD en el ecotipo Antártico podría explicar que la actividad SOD total registrada en el mismo sea mayor y se mantenga por más tiempo durante el tratamiento severo de UV-B.
No obstante ser causantes de estrés oxidativo, a baja concentración las EAOs constituyen parte del proceso de transducción de señales asociadas a la aclimatación al estrés ambiental (Zhou et al. 2007, Poage et al. 2011). Considerando el rol dual de las EAOs, la mantención de su homeostasis celular constituye una propiedad muy importante de las plantas sometidas a estrés ambiental y está directamente relacionada con su capacidad antioxidante (Dat et al. 2000, Lütz 2010). C. quitensis habita en regiones con episodios propicios para la generación de EAOs: alta radiación PAR, UV-B y baja temperatura. Una elevada capacidad antioxidante sería determinante en la capacidad de esta planta de sobrevivir en ambientes propicios para la generación de estrés oxidativo (Xiong et al. 1999, Bravo et al. 2001).

Morfológicamente, ambos ecotipos mostraron ser plásticos, es decir, ambos ecotipos modificaron su anatomía foliar de manera consistente con una posible disminución de los efectos negativos de la exposición a alta radiación UV-B. En ambos ecotipos se evidenció una disminución tanto en el largo como en el ancho foliar, sugiriendo 
que una condición de alta radiación UV-B induce un menor crecimiento en estos órganos. Por ejemplo, Hofmann \& Campbell (2011) mostraron que la especie Trifolium repens sometida a un aumento en la radiación UV-B presenta un menor tamaño foliar y un menor número de hojas, esto también se ha observado en Arabidopsis thaliana, lo que se ha asociado a un efecto sobre la expansión celular en los estados iniciales del desarrollo de la hoja (Hectors et al. 2007). Adicionalmente, el grosor tanto del mesófilo como del parénquima esponjoso y de empalizada fue significativamente mayor en los individuos de ambos ecotipos de $C$. quitensis bajo una condición de alta radiación UV-B. Este efecto ha sido demostrado con anterioridad (Newsham \& Robinson 2009) y ha sido sugerido como una estrategia que presentan las plantas para aumentar la barrera mecánica a los rayos UV, evitando daños al aparato fotosintético (Basiouny et al. 1978, Hideg 2002). El hecho que el ecotipo Antártico presente un grosor del parénquima esponjoso y en empalizada significativamente mayor independientemente del tratamiento de UV-B (Tabla 1 y 2), sugiere que dicho ecotipo posee una protección estructural que podría relacionarse con la menor capacidad de respuesta bioquímica (TAS, SOD) que manifiesta el ecotipo Antártico frente a los tratamientos de UV-B.

Las mediciones del daño por estrés oxidativo, tanto a nivel de membranas (MDA), como de aparato fotosintético (Fv/Fm, Phi), muestran un menor daño en el ecotipo Andino que en el Antártico, el cual a $15{ }^{\circ} \mathrm{C}$ muestra el máximo de daño a membranas (Fig. 4). Los niveles de MDA en ambos ecotipos no muestran diferencias significativas atribuibles al origen o temperatura.

Es interesante destacar que en el ecotipo Antártico, el daño a nivel de membranas y el observado a nivel del aparato fotosintético responden diferencialmente a la temperatura. El decaimiento fotosintético fue mayor a baja temperatura, mientras que la peroxidación lipídica ocurrió con mayor intensidad a $15{ }^{\circ} \mathrm{C}$. Esto probablemente se relacione con que el efecto del UV-B sobre la peroxidación lipídica es una reacción en cadena dependiente de la temperatura, es decir, la baja temperatura no congelante estabilizaría las membranas, mientras que a nivel del aparato fotosintético la radiación UV-B puede interferir a nivel algunos componentes del transporte de electrones tales como: quinonas, complejo de manganesos asociado al complejo hidrolítico del agua (Jansen et al. 1998), manteniendo la capacidad fotofísica de capturar energía lumínica. Esto provocaría un aumento de la presión de excitación del PSII con la consiguiente fotoinhibición, especialmente en hojas adaptadas a condiciones lumínicas menos intensas, tales como en el ecotipo Antártico (Bravo et al. 2007).

La mayor fotoinactivación (Phi) que sufre el ecotipo Antártico producto del tratamiento UV-B también se relaciona con que estos ecotipos poseen estrategias fotoprotectoras distintas. Mientras el ecotipo Andino favorece una evasión de la absorción lumínica y su posterior disipación del exceso de energía absorbida en forma de calor, el ecotipo Antártico maximiza la captura y la utilización fotoquímica de la energía (Bravo et al. 2007, Bascuñán-Godoy et al. 2010) con lo cual el efecto del UV-B sobre los componentes asociados al transporte de electrones del PSII pueden ser más severos (Jansen et al. 1998). No obstante lo anterior, los niveles de Fv/Fm observados en ambos ecotipos no denotan un daño permanente al PSII, lo que queda demostrado por la recuperación de los valores iniciales de $\mathrm{Fv} / \mathrm{Fm}$ pasadas 12 horas en ausencia de radiación UV-B, sugiriendo que el descenso de la eficiencia fotoquímica máxima se trata de una respuesta regulatoria que permite disminuir el exceso de energía absorbido, limitando el potencial daño al aparato fotosintético. Las variaciones de $\mathrm{Fv} / \mathrm{Fm}$ observadas son consistentes con variaciones estacionales medidas en terreno en ambos ecotipos, lo que refuerza la idea que no se debiera atribuir a un daño importante del aparato fotosintético y que estaría dentro de los rangos normales de sobrevivencia de la especie en su hábitat natural (Casanova-Katny 2006, Xiong et al. 1999). Asimismo, nuestros resultados muestran que el ecotipo Andino presenta menos daño a nivel de membranas $\mathrm{y}$ del aparato fotosintético.

Estos resultados confirman nuestra hipótesis: el ecotipo Andino presenta una respuesta antioxidante más efectiva contra el UV-B que el ecotipo Antártico, dado que sufre menos daño en sus membranas, 
conserva una mayor reserva de antioxidantes totales, responde más rápido aumentando su contenido de SOD y muestra un menor grado de fotoinactivación en concordancia con los niveles de radiación UV-B al cual están expuestos ambos ecotipos en sus respectivos hábitats. No obstante, el ecotipo antártico muestra una tolerancia a niveles radiación UV-B que superan más de diez veces los niveles normales en su hábitat, permitiendo afirmar que los aumentos de radiación generados por el adelgazamiento de la capa de ozono en la Antártida no afectarían negativamente a las poblaciones de este ecotipo. Los resultados, además confirman la diferenciación ecotípica entre las poblaciones de C. quitensis estudiadas, propuesta por Gianoli et al. (2004), dado que a pesar del extenso periodo bajo condiciones de jardín común ambas procedencias mostraron respuestas fisiológicas bioquímicas y morfológicas claramente diferentes.

AGRADECIMIENTOS: Este estudio fue financiado por los proyectos FONDECYT 1010899 y FONDECYT 1060910. Marco A. Molina-Montenegro agradece al proyecto INACH T_14_08.

\section{LITERATURA CITADA}

ALSCHER RG, N ERTURK \& LS HEATH (2002) Role of superoxide dismutases (SODs) in controlling oxidative stress in plants. Journal of Experimental botany 53: 1331-1341.

ASADA K (1999) The water-water cycle in chloroplasts: Scavenging of active oxygens and dissipation of excess photons. Annual Review of Plant Physiology and Plant Molecular Biology 50: 601639.

BABU TS, TA AKHTAR, MA LAMPI, S TRIPURANTHAKAM，DG DIXON \& BM GREENBERG (2003) Similar stress responses are elicited by copper and ultraviolet radiation in the aquatic plant Lemna gibba: Implication of reactive oxygen species as common signals. Plant \& Cell Physiology 44: 1320-1329.

BASCUÑÁN-GODOY L, JI GARCÍA-PLAZAOLA, LA BRAVO \& LJ CORCUERA (2010) Leaf functional and micro-morphological photoprotective attributes in two ecotypes of Colobanthus quitensis from the Andes and Maritime Antarctic. Polar Biology 33: 885-896.

BASIOUNY FM, TK VAN \& RH BIGGS (1978) Some Morphological and Biochemical Characteristics of C3 and C4 Plants Irradiated with UV-B. Physiologia Plantarum 42: 29-32.

BRAVO LA, N ULLOA, GE ZÚÑIGA, A CASANOVA, LJ CORCUERA \& M ALBERDI (2001) Cold resistance in Antarctic angiosperms. Physiologia Plantarum 111: 55-65.

BRAVO LA, FA SAAVEDRA-MELLA, F VERA, A GUERRA, LA CAVIERES, AG IVANOV, NP
HUNER \& LJ CORCUERA (2007) Effect of cold acclimation on the photosynthetic performance of two ecotypes of Colobanthus quitensis (Kunth) Bartl. Journal of Experimental Botany 58: 35813590.

CABRERA S, S BOZZO \& H FUENZALIDA (1995) Variations in UV radiation in Chile. Journal of Photochemistry and Photobiology B Biology 28: 137-142.

CARRASCO-RÍOS L (2009) Efecto de la radiación ultravioleta-b en plantas. Idesia 27: 59-76.

CASANOVA-KATNY MA, LA BRAVO, MA MOLINAMONTENEGRO, LJ CORCUERA \& LA CAVIERES (2006) Photosynthetic performance of Colobanthus quitensis (Kunth) Bartl. (Caryophyllaceae) in a high-elevation site of the Andes of central Chile. Revista Chilena de Historia Natural 79: 41-53.

CAVIERES LA, EI BADANO, A SIERRA-ALMEIDA \& MA MOLINA-MONTENEGRO (2007) Microclimatic modifications of cushion plants and their consequences for seedling survival of native and non-native herbaceous species in the high Andes of Central Chile. Arctic Antarctic and Alpine Research 39: 229-236.

DAT JS, VAN DENABEELE, E VRANOVÁ, M VAN MONTAGU, D INZÉ \& F VAN BREUSEGEM (2000) Dual action of the active oxygen species during plant stress responses. Cellular and Molecular Life Sciences 57: 779-795.

DAY TA, CT RUHL \& FS XIONG (2001) Influence of solar ultraviolet-B radiation on Antarctic terrestrial plants: Results from a 4-year field study. Journal of Photochemistry and Photobiology B Biology 62: 78-87.

DHINDSA RS, PL PLUMB-DHINDSA \& DM REID (1982) Leaf senescence and lipid peroxidation: Effects of some phytohormones and scavengers of free radicals and singlet oxygen. Physiologia Plantarum 56: 453-457.

FAGERBERG WR \& JF BORNMAN (2005) Modification of leaf cytology and anatomy in Brassica napus grown under above ambient levels of supplemental UV-B radiation Photochemical \& photobiological sciences: Photochemical \& Photobiological Sciences 4: 275-279.

FEDINA I, J HIDEMA, M VELITCHKOVA, K GEORGIEVA \& D NEDEVA (2010) UV-B induced stress responses in three rice cultivars. Biologia Plantarum 54: 571-574.

FRYER MJ, K OXBOROUGH, PM MULLINEAUX \& NR BAKER (2002) Imaging of photo-oxidative stress responses in leaves. Journal of Experimental Botany 53: 1249-1254.

GIANOLI E, P INOSTROZA, A ZÚÑIGA-FEEST, M REYES-DÍAZ, LA CAVIERES, LA BRAVO \& LJ CORCUERA (2004) Ecotypic differentiation in morphology and cold resistance in populations of Colobanthus quitensis from the Andes of central Chile and the maritime Antarctic. Arctic Antarctic and Alpine Research 36: 484-489.

GILL SS \& N TUTEJA (2010) Reactive oxygen species and antioxidant machinery in abiotic stress tolerance in crop plants. Plant Physiology and Biochemistry 48: 909-930.

GREEN TGA, B SCHROETER \& LG SANCHO (2007) Plant life in Antarctica. En: Pugnaire F \& F Valladares (eds) Functional Plant Ecology:389-433. Segunda edición. CRC Press, Boca Raton. 
HECTORS K, E PRINSEN, W DE COEN, MA JANSEN \& Y GUISEZ (2007) Arabidopsis thaliana plants acclimated to low dose rates of ultraviolet $\mathrm{B}$ radiation show specific changes in morphology and gene expression in the absence of stress symptoms. The New Phytologist 175: 255-70.

HIDEG E (2002) Detection of singlet oxygen and superoxide with fluorescent sensors in leaves under stress by photoinhibition or UV radiation. Plant and Cell Physiology 43: 1154-1164.

HOFMANN RW \& BD CAMPBELL (2011) Response of Trifolium repens to UV-B radiation: Morphological links to plant productivity and water availability. Plant Biology (Stuttg) 13: 896-901.

HUNER NP, G ÖQUIST \& F SARHAN (1998) Energy balance and acclimation to light and cold. Trends in Plant Science 3: 224-230.

JANSEN MA, V GABA \& BM GREENBERG (1998) Higher plants and UV-B radiation: Balancing damage repair and acclimation. Trends in Plant Science 3: 131-135.

JORDAN BR (1996) Molecular response of plant cells to UV-B stress. Functional Plant Biology 29: 909-916.

KARPINSKA B, M KARLSSON, H SCHINKEL, S STRELLER, KH SÜSS, M MELZER \& G WINGSLE (2001) A novel superoxide dismutase with a high isoelectric point in higher plants expression regulation and protein localization. Plant Physiology 126: 1668-1677.

KATARIA S, K JAIN \& KN GURUPRASAD (2007) UV-B induced changes in antioxidant enzymes and their isoforms in cucumber (Cucumis sativus L) cotyledons. Indian Journal of Biochemistry \& Biophysics 44: 31-37.

KEREN N \& A KRIEGER-LISZKAY (2011) Photoinhibition: Molecular mechanisms and physiological significance. Physiologia Plantarum 142: $1-5$.

LARCHER W (2000) Temperature stress and survival ability of Mediterranean sclerophyllous plants. Plant Biosystems 134: 279-295.

LÜTZ C (2010) Cell physiology of plants growing in cold environments. Protoplasma 244: 53-73.

MACKERNESS SA, HCF JOHN, B JORDAN \& B THOMAS (2001) Early signaling components in ultraviolet-B responses: Distinct roles for different reactive oxygen species and nitric oxide. FEBS Letters 489: 237-242.

MADRONICH S, R MCKENZIE, L BJORN \& M CALDWELL (1998) Changes in biologically active ultraviolet radiation reaching the Earth's surface. Journal of Photochemistry and Photobiology B 46: 5-19.

MCCORD JM, \& I FRIDOVICH (1969) Superoxide dismutase an enzymic function for erythrocuprein (hemocuprein). Journal of Biological Chemistry 244: 6049-6055.

MILLER NJ, C RICE-EVANS \& MJ DAVIES (1993) A new method for measuring antioxidant activity. Biochemical Society Transactions 21: 95-101.

MOLINA-MONTENEGRO MA \& LA CAVIERES (2010) Variación altitudinal de los atributos morfo-fisiológicos en dos especies de plantas alto-andinas y sus implicancias contra la fotoinhibición. Gayana Botánica 67: 1-11.

MOLINA-MONTENEGRO MA, C TORRES-DÍAZ, F CARRASCO-URRA, L GONZÁLEZ-SILVESTRE \& E GIANOLI (2012) Plasticidad fenotípica en dos poblaciones antárticas de Colobanthus quitensis
(Caryophyllaceae) bajo un escenario simulado de cambio global. Gayana Botánica 69: 152-160.

MOORE DM (1970) Studies in Colobanthus quitensis (Kunth) Bart and Deschampsia antarctica Desv II Taxonomy distribution and relation. British Antartic Survey Bulletin 23: 63-80.

MUSIL CF (1996) Accumulated effect of elevated ultraviolet-B radiation over multiple generations of the arid-environment annual Dimorphotheca sinuata DC (Asteraceae). Plant Cell and Environment 19: 1017-1027.

NEWSHAM KK \& SA ROBINSON (2009) Responses of plants in polar regions to UVB exposure: A metaanalysis. Global Change Biology 15: 2574-2589.

PEREZ-TORRES, LA BRAVO, LJ CORCUERA \& J DINAMARCA (2004) Responses of Colobanthus quitensis (Kunth) Bartl to high light and low temperature. Polar Biology 27: 183-189.

POAGE MB, LE MARTRET, MAK JANSEN, GD NUGENT \& PJ DIX (2011) Modification of reactive oxygen species scavenging capacity of chloroplasts through plastid transformation. Plant Molecular Biology 76: 371-384.

RADYUKINA NL, AV SHASHUKOVA, SS MAKAROVA \& VV KUZNETSOV (2011) Exogenous proline modifies differential expression of superoxide dismutase genes in UV-B-irradiated Salvia officinalis plants. Russian Journal of Plant Physiology 58: 51-59.

RAO M, G PALIYATH \& DP ORMROD (1996) Ultraviolet-B- and ozone-induced biochemical changes in antioxidant enzymes of Arabidopsis thaliana Plant physiology 110: 125-136

ROBBERECHT R \& MM CALDWELL (1983) Protective mechanisms and acclimation to solar ultraviolet-B radiation in Oenothera stricta. Plant Cell and Environment 6: 477-485.

ROBINSON SA, J WASLEY \& AK TOBIN (2003) Living on the edge-plants and global change in continental and maritime Antarctica. Global Change Biology 9: 1681-1717.

ROZEMA JJ, VAN DE STAAIJ, LO BJÖRN \& M CALDWELL (1997) UV-B as an environmental factor in plant life: Stress and regulation. Trends in Ecology \& Evolution 12: 22-28.

SANTIBÁÑEZ F \& J URIBE (1990) Atlas agroclimático de Chile: Regiones V y Metropolitana. Ediciones Universidad de Chile, Santiago, Chile.

SCHÖNER S \& G KRAUSE (1990) Protective systems against active oxygen species in spinach: Response to cold acclimation in excess light. Planta 180: 383-389.

SHI SB, YX SHANG PJ, ZHU \& DG ZHANG (2011) Effects of strong solar UV-B radiation on photosynthesis and photosynthetic pigment contents of Saussurea superba on Qinghai-Tibet Plateau. Ying Yong Sheng Tai Xue Bao 22: 53-60.

SIERRA-ALMEIDA Á, MA CASANOVA-KATNY, LA BRAVO, LJ CORCUERA \& LA CAVIERES (2007) Photosynthetic responses to temperature and light of Antarctic and Andean populations of Colobanthus quitensis (Caryophyllaceae). Revista Chilena de Historia Natural 80: 335-343.

STAPLETON AE (1992) Ultraviolet radiation and plants: Burning questions. The Plant Cell 4: 1353-1358.

TERAMURA AH \& JH SULLIVAN (1994) Effects of UV-B radiation on photosynthesis and growth of terrestrial plants. Photosynthesis Research 39: $463-473$ 
TSANG EW, C BOWLER, D HÉROUART, W VAN CAMP, R VILLARROEL, C GENETELLO, M VAN-MONTAGU \& D INZÉ (1991) Differential regulation of superoxide dismutases in plants exposed to environmental stress. The Plant Cell 3: 783-792.

VERA F (2003) Actividad antioxidante enzimática de superóxido dismutasa y su relación con la presión de excitación del Fotosistema II en Colobanthus quitensis. Tesis de Pregrado, Facultad de Ciencias Naturales y Oceanográficas, Universidad de Concepción, Concepción, Chile.

WANG S, B XIE, L YIN, L DUAN, Z LI, AE ENEJI, W TSUJI \& A TSUNEKAWA (2010) Increased UV-B radiation affects the viability reactive oxygen species accumulation and antioxidant enzyme activities in maize (Zea mays L. ) pollen. Photochemistry and Photobiology 86: 110-116.

XIONG F, C RUHLAND \& T DAY (1999) Photosynthetic temperature response of the Antarctic vascular plants Colobanthus quitensis and Deschampsia antarctica. Physiologica Plantarum 106: 276-286.

ZAR JH (1999) Biostatistical analysis. Fourth edition. Prentice Hall, Englewood Cliffs, New Jersey.

ZHOU X, G WANG \& W ZHANG (2007) UV-B responsive microRNA genes in Arabidopsis thaliana. Molecular Systems Biology 3: 103.

ZULFUGAROV IS, A TOVUU, JH KIM \& CH LEE (2011) Detection of reactive oxygen species in higher plants. Journal of Plant Biology 54: 351-357.

Responsabilidad editorial: Álvaro T. Palma

Recibido el 18 de noviembre de 2011; aceptado el 5 de diciembre de 2012 
